\title{
海綿静脈洞部硬膜動静脈瘻に対する経静脈的塞栓術における アクセス困難な海綿静脈洞部へのグースネックスネアを用いた マイクロカテーテル・プルアップ法
}

\author{
長谷川仁 ${ }^{1)}$ 伊藤 $\quad$ 靖 $^{2)}$ 本道洋昭 ${ }^{3)}$ 反町隆俊 ${ }^{2)} \quad$ 藤井幸彦 ${ }^{2)}$
}

\section{Microcatheter pull-up technique using gooseneck snare in transvenous embolization for cavernous sinus dural arteriovenous fistula: technical note}

\author{
Hitoshi HASEGAWA ${ }^{1)}$ Yasushi ITO $^{2)}$ Hiroaki HONDO ${ }^{3)}$ Takatoshi SORIMACHI ${ }^{2)}$ Yukihiko FUJII ${ }^{2)}$ \\ 1) Department of Neurosurgery, Kuwana Hospital, Niigata \\ 2) Department of Neurosurgery, Brain Research Institute, University of Niigata, Niigata \\ 3) Department of Neurosurgery, Toyama Prefectural Central Hospital, Toyama
}

\begin{abstract}
O
Objective: The authors report a case of cavernous sinus dural arteriovenous fistula (CS dAVF) treated by transvenous embolization (TVE) using microcatheter pull-up technique.

Case presentation: A 76-year-old woman with dAVF in the bilateral CS underwent transvenous embolization of the right CS. The right inferior petrosal sinus could not be reached using a 0.035 -inch guidewire via the right internal jugular vein (IJV) where a guiding catheter was located. Then, a guiding catheter was relocated in the left IJV. A guidewire reached the right inferior petrosal sinus (IPS) through the left IPS and the posterior intercavernous sinus. The guidewire could go proximally in the left IPS to the right IJV, though it could not pass distally into the right IPS. The guidewire in the right IJV was caught using a gooseneck snare through a coaxial microcatheter, which was introduced via another guiding catheter located in the right IJV. By pulling the guidewire, the gooseneck snare was pulled up with the microcatheter into the right IPS, then the microcatheter could reach the right CS. Embolization of the right CS with platinum coils through the microcatheter resulted in complete disappearance of the CS dAVF. The patient's symptoms improved 2 weeks after the procedure.

Conclusion: Microcatheter pull-up technique might be effective to reach an affected CS during transvenous embolization of CS dAVF, when a microcatheter could not be introduced into the CS by an ordinary method.
\end{abstract}

Key Words

dural arteriovenous fistula, gooseneck snare, pull-up technique

1) 桑名病院 脳神経外科

2) 新潟大学脳研究所脳神経外科

3）富山県立中央病院 脳神経外科

<連絡先：長谷川仁 $=950-0032$ 新潟市東区河渡甲 140 番地 E-mail : jin-hase@dk9.so-net.ne.jp >

(Received January 25, 2011 : Accepted May 14, 2011)

\section{緒 言}

海綿静脈洞部硬膜動静脈瘦（cavernous sinus dural arteriovenous fistula : CS dAVF) に対する経静脈的塞栓 術（transvenous embolization：TVE）は，根治性から 第一選択の治療法となっている ${ }^{1,3,6,8)}$. TVE では多くの 場合患側の内頝静脈（internal jugular vein：IJV）から 下錐体静脈洞（inferior petrosal sinus：IPS）経由でマイ クロカテーテルをCS内へ誘導し，プラチナコイルを用 いて CS を塞栓する. その際, IPS が血管造影で描出さ れないような例でも，ガイドワイヤーでIPSが走行する と考えられるルートを貫通させた後にマイクロカテーテ 
ルを誘導して海綿静脈洞に到達できることが多いことが 報告されている3)。 またIPS を通過しない場合には，直 接切開または経カテーテルで顔面静脈から上眼静脈 (superior ophthalmic vein：SOV）を経由してCS 内にマ イクロカテーテルを誘導する方法 ${ }^{1)}$ や，開頭後にシル ビウス静脈を穿刺してマイクロカテーテルを誘導する方 法 $^{8)}$, 海綿静脈洞の直接切開などが報告されている ${ }^{2)}$. しかしこれらの方法は侵襲が大きいため，可能であれば カテーテルによるIPS を経由したアプローチが望まし い.

我々は，治療側の IPS が血管造影で描出されず通常の 方法ではアクセスできないCS dAVF の症例に対し, 0.035 インチラジフォーカスガイドワイヤー（Terumo, Tokyo）で対側 IPS から posterior intercavernous sinus を介して治療側 IPS，さらに内䅡静脈に到達し，このガ イドワイヤーをグースネックスネア（MTI-ev3, Irvine, CA, USA）で捕捉することで治療側 IPS 内にマイクロカ テーテルを誘導し，さらに治療側 CS に到達してTVE を行い根治させることができた 1 例を経験した，本方法 はマイクロカテーテル・プルアップ法として報告されて いるが 6)，本例で用いたテクニックを中心に報告する.

\section{症例呈示}

症例 : 76 歳, 女性.

主訴：右眼球結膜充血, 眼球突出.

現病歴：3力月前から右眼球結膜充血を自覚し，1力月前 に近医眼科を受診、頭蓋内疾患を疑われ当科を紹介され た. MRI/ MRA (magnetic resonance imaging/ magnetic resonance angiogram) で CS 内の多数の flow void および拡張した右 SOV を認め, 症状と併せて CS dAVF と診断され, 加療目的で入院した.

入院時神経学的所見: 右眼球結膜充血, 眼球突出およ び眼窩部血管雑音を認めた。他に神経脱落症状はなか った，脳血管造影（Fig. 1) では，両側内䅡動脈の meningohypophyseal trunk, 両側外澒動脈の主に中硬膜 動脈，左椎骨動脈のから odontoid branchを介した lateral clival branch を流入動脈とし, 右 SOV と右 uncal vein および左 IPSを流出静脈路とする両側性の CS dAVF を認めた．右 IPS は血管造影では描出されなかっ た.

\section{1. 治療方針}

症状を呈する右 CS の流出静脈路の塞栓を優先して行
うこととして, 血管造影では描出されない右 IPS 経由で, 経静脈的に右 CS のコイル塞栓を行う方針とした.

\section{2. 血管内手術}

1）初回 TVE

局所麻酔下に大腿静脈経由で右 IJVに 5 Fr Envoy （Cordis, Miami, FL, USA）を留置した。造影されない右 IPS に対して 0.035 インチガイドワイヤーによる貫通や, 0.016 インチマイクロガイドワイヤー（GTワイヤー, Terumo, Tokyo）とマイクロカテーテルの組み合わせに よる貫通を試みたが，右 IPSを通過できなかった。ささら に患側顔面静脈を介した右 SOV 経由や左 IPS から intercavernous sinus を経由するルートからのアクセス を試みたが，いずれの方法でも右 CS 到達できなかっ た．左 IPS には容易に 0.035 インチガイドワイヤーを進 めることができたが，それまでの手技が長時間に及んだ ために, 左 IPS から intercavernous sinus や basilar plexus を介したアプローチは局所麻酔下では充分に時間をかけ て試みることができず，一旦治療を中止せざるを得なか った。

\section{2) 2 回目 TVE (Fig. 2)}

2 回目は, 初回 TVE の手技後半に試み, 最も到達で きる可能性が高いと思われた経路を最初から選択して手 技を開始した。すなわち，左 IPSからアプローチし， intercavernous sinus または basilar plexus を経由し右 CS 内へ到達するルートを再度試みる方針とした，局所麻酔 下に右大腿静脈穿刺を行った。左 IJVへ 5 Fr Envoy を 留置し， 0.035 インチガイドワイヤーにて左 IPS からア クセスすると，スムーズに posterior intercavernous sinus を経由し右 IPS 内に進めることができた。しかし， 何度試みても posterior intercavernous sinus から右 CS 方向には同ワイヤーを誘導できなかった。同ワイヤーは 右 IPS 内を尾側に向かい右 IJV には抵抗なく誘導でき た：そこで方針を転換し，左大腿静脈を穿刺して右 IJV に5Fr Envoy を留置し, 同カテーテルから Renegade 18 マイクロカテーテル (Boston scientific, Natick, MA, USA）と同軸に中を通したグースネックスネア $4 \mathrm{~mm}$ を 使い，右 IJV 内で前述の 0.035 インチガイドワイヤーを 捕捉した。このガイドワイヤーを引き戻すことで Renegade18 とスネアを右 IPS 下端部に引き上げながら 誘導した。 その後スネアを 0.016 インチ GT マイクロガ イドワイヤーに交換した．マイクロガイドワイヤーは右 IPS から右 CS に誘導できたが，外径 2.3Fr の Renegade 

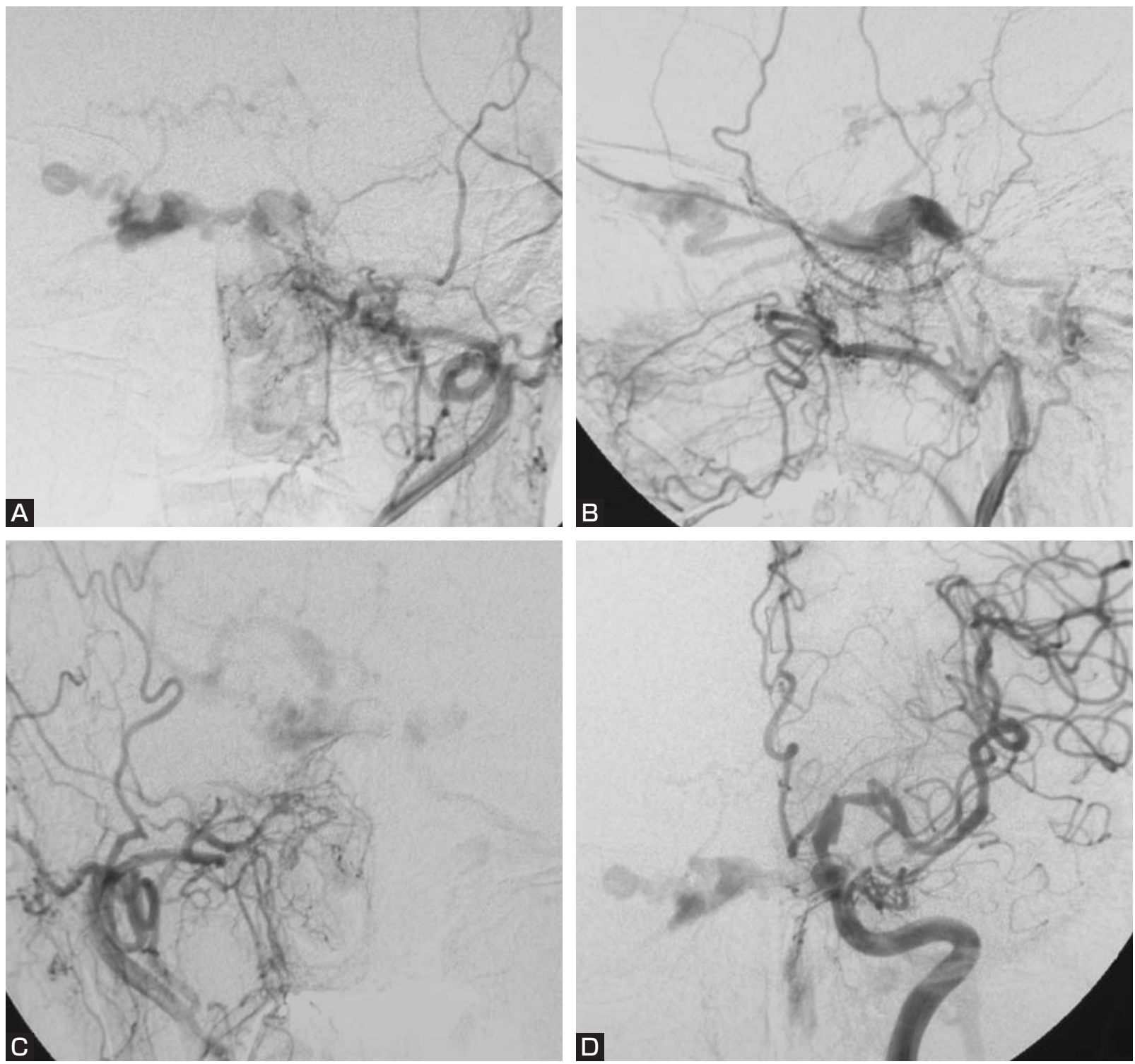

Fig. 1 Cerebral angiograms demonstrating cavernous sinus dural arteriovenous fistula (CS dAVF).

A, B : A left external carotid angiogram (anteroposterior view : A ; lateral view : B) showing CS dAVF. The right superior ophthalmic vein, right uncal vein and left inferior petrosal vein (IPS) are main venous drainage routs from the dAVF.

C : A right external carotid angiogram. The accessory meningeal artery and the middle meningeal artery are the main feeders to the dAVF.

D : A left internal carotid angiogram (anteroposterior view) showing CS dAVF supplied by the meningohypophyseal trunks.

18 は右 IPS と IJV の合流部からはマイクロガイドワイ ヤーに追従せず右 IPS 内を進まなかった。 そこで, Synchro $10300 \mathrm{~cm}$ ロングガイドワイヤー (Boston scientific, Natick, MA, USA）を用いて外径 2.3Fr の Renegade 18 を外径 1.7Fr の Echelon 10 (MTI-ev3, Irvine, CA，USA）に交換したところ，IPS と IJV の合流部の通 過が可能となりマイクロカテーテルを右 IPS 内に誘導で
き,さらにマイクロカテーテルの先端を右 CS 内に留 置できた. CS 内に留置した Echelon 10 を介しプラチ ナコイルで右 CS を塞栓した. GDC (Boston scientific, Natick, MA, USA) と Detach 11 (COOK, Bloomington, Ind., USA）を合計 $261 \mathrm{~cm}$ 用いて右 CS を閉塞し，動静 脈瘻のシャントが消失したため手技を終了した（Fig. 3). 

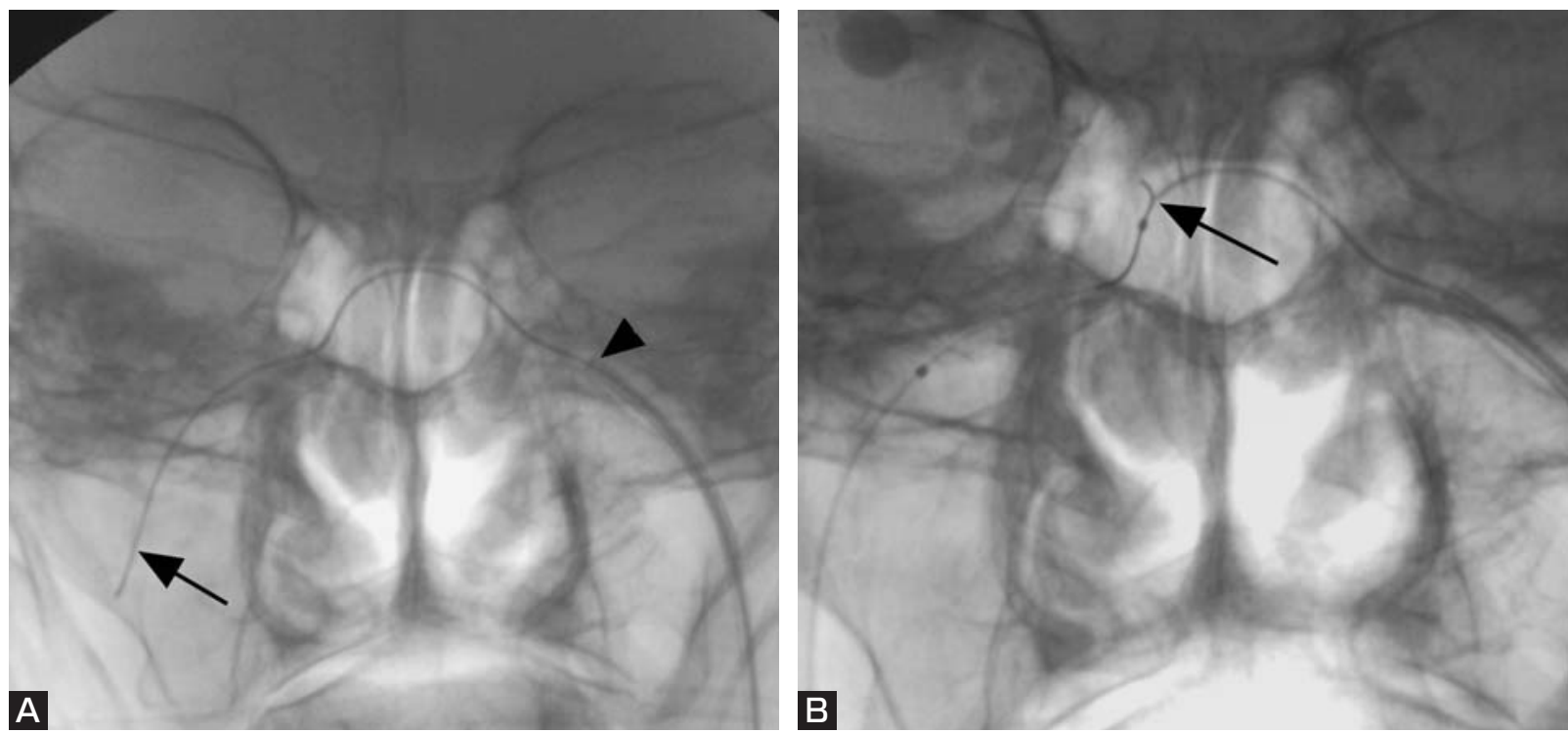

Fig. 2

A : A craniogram showing a guidewire (arrows), which advances from the left inferior petrosal vein (IPS) to the right internal jugular vein (IJV) through the posterior intercavernous sinus and the right IPS. A tip of a guiding catheter (arrow head) is located in the left IJV.

B : A craniogram showing a gooseneck snare with a coaxial microcatheter pulled up into the right IPS by pulling the guidewire, which is caught by the gooseneck snare (arrow).

\section{3）術後経過}

右眼窩部血管雑音は術直後から，右眼球結膜充血，眼 球突出は術後 2 週間で消失し社会復帰した。その後 3 年 間の経過観察でも症状の再発はない.

\section{考 察}

現在，CS dAVF に対し TVE は根治的な治療である ため第一に選択される治療法となっているが ${ }^{1,3,6,8)}$ ，罹患 静脈洞へのアプローチルートである IPS が血管造影で 描出されず到達困難な症例があることが大きな問題の一 つである，造影されない IPS をガイドワイヤーに回転 トルクをかけながら進めて貫通しマイクロカテーテルを 到達させたり，対側の静脈洞など他のルートからアプ ローチすることで治療可能な場合も多いと報告されてい

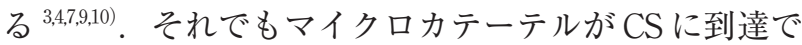
きない場合は，開頭による direct sinus packing ${ }^{2)}$ や開頭 後シルビウス静脈直接穿刺 ${ }^{8)}$ などの侵襲的な方法が有 効なこともある. また経静脈的塞栓術ができない場合は, 経動脈的塞栓術でシャント流量を減少させたり放射線照 射を行うこともあるが，根治的な治療とならないことが 多い5,13).

本例では，IPSを血流に逆行する通常のルートでは
CSにアプローチできず，対側 IPSから posterior intercavernous sinus を介して IPS を血流に順行する方 向にガイドワイヤーを通し，さらにグースネックスネア でこのガイドワイヤーを捕捉することで CS に到達でき た. Hanaoka らは我々と同様の方法で CS に到達し治療 できたCS dAVF の 1例を microcatheter pull-up technique として報告している ${ }^{6)}$. ただし注意すべき点として，本 例では 0.035 インチのガイドワイヤーで対側 IPS からア クセスルートを探り，患側 IPS に到達できたために，ル 一トを確保している同ワイヤーを抜かずにそのまま用い て手技を遂行したが，頭蓋内静脈洞で使用するガイドワ イヤーとしてはプロファイルが大きいと言わざるを得な い. マイクロカテーテルとマイクロガイドワイヤーに交 換してアクセスを試みた方がより安全であり，またプロ ファイルが小さくなるために posterior intercavernous sinus から容易にCS 内へアプローチできた可能性も否 定できないと思われた。

IPS を含む頭蓋内静脈洞には隔壁があり，この隔壁を 通って静脈血がCS から IPS を介して IJV に流出する ${ }^{11)}$. 本例のようにCS から IPS へ到達する場合は，この静脈 の流れに順行性にガイドワイヤーが通過するため, IJV から CSへと逆行性に通過する場合よりも隔壁に妨げら 

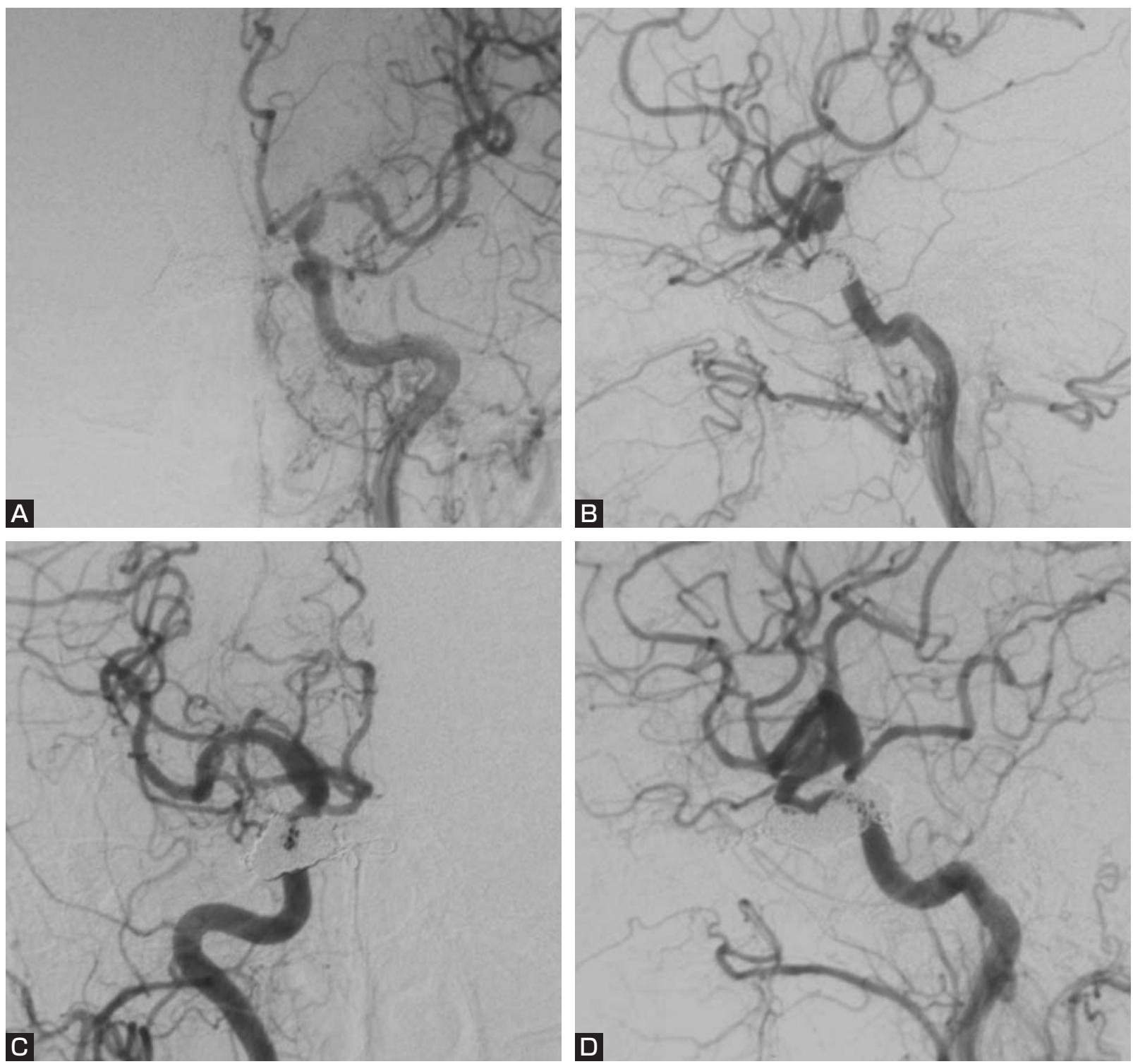

Fig. 3 Bilateral common carotid angiograms immediately after embolization of the right cavernous sinus showing disappearance of cavernous sinus dural arteriovenous fistula.

A, B : A left common carotid angiogram (anteroposterior view : A ; lateral view : B).

$\mathrm{C}, \mathrm{D}: \mathrm{A}$ right common carotid angiogram (anteroposterior view : C ; lateral view : D)

れる可能性が少なく, 通過しやすかったものと思われた. またRhotonらによれば，IPSとIJVの合流部は直径 2-3 mm の main channel と $1 \mathrm{~mm}$ 以下の複数の小さな channelにより confluenceを構成している ${ }^{12}$. IJVから IPSへのカテーテリゼーションに際し, main channel で なく小さな channel にガイドワイヤー先端が入った場合 には，IJVから IPSへ向けてガイドワイヤーやカテーテ ルを進めることが困難になるとも考えられる，プルアッ プ法では血流に順行してガイドワイヤーが進むため, main channel に入りやすい可能性もある. 大腿静脈穿刺
による血管内治療だけで行える本方法は, 直接穿刺など の侵襲的な方法や経動脈的塞栓術のような姑息的な方法 を行う前に考慮するべき方法と思われた。

\section{結 語}

グースネックスネアを用いたマイクロカテーテル・プ ルアップ法は, 通常の方法でIPS を経由し CSヘアクセ スできない症例に有効な場合がある。開頭による直接穿 刺などの侵襲的な方法や経動脈的塞栓術のような姑息的 な方法を行う前に，考慮するべき方法と思われた． 


\section{文 献}

1) Biondi A, Miela D, Cognard C, et al: Cavernous sinus dural fistulae treated by transvenous approach through the facial vein: report of seven cases and review of the literature. AJNR 24:1240-1246, 2003.

2) Day JD, Fukushima T: Direct microsurgery of dural arteriovenous malformation type carotid-cavernous sinus fistulas: indications, technique, and results. Neurosurgery 41:1119-1124, 1997.

3) Benndorf G, BenderA, Lehmann R, et al: Transvenous occlusion of dural cavernous sinus fistulas through the thrombosed inferior petrosal sinus: report of four cases and review of the literature. Surg Neurol 54:42-54, 2000.

4) Wong GK, Poon WS, Yu SC, et al: Transvenous embolization for dural transverse sinus fistulas with occluded sigmoid sinus. Acta Neurochir (Wien) 149:929936, 2007

5) Guo WY, Pan DH, Wu HM, et al: Radiosurgery as a treatment alternative for dural arteriovenous fistulas of the cavernous sinus. AJNR 19:1081-1087, 1998.

6) Hanaoka M, Satoh K, Satomi J, et al: Microcatheter pullup technique in the transvenous embolization of an isolated sinus dural arteriovenous fistula. $J$ Neurosurg 104:974-977, 2006.

7) Komiyama M, Ishiguro T, Matsusaka Y, et al: Transfemoral, transvenous embolisation of dural arteriovenous fistula involving the isolated transverse-sigmoid sinus from the contralateral side. Acta Neurochir (Wien) 144:1041-1046, 2002.

8) Kuwayama N, Endo S, Kitabayashi M, et al: Surgical transvenous embolization of a cortically draining carotid fistula via a vein of the sylvian fissure. AJNR 19:13291332, 1998.

9) Matsuzaki T, Shibuya T, Suma T, et al: 逆行性静脈造影 で pseudo-occlusionを確認後 transvenous embolization で治療した isolated 横静脈洞 S 状静脈洞硬膜動静脈瘻の 1 例. No Shinkei Geka 37:1221-1225, 2009.

10) Naito I, Iwai T, Shimaguchi H, et al: Percutaneous transvenous embolisation through the occluded sinus for transverse-sigmoid dural arteriovenous fistulas with sinus occlusion. Neuroradiology 43:672-676, 2001.

11) Newton TH, Potts DG: Radiology of the skull and brain. Angiography Volume Two / Book 3. Saint Louis, The C. V. Mosby Company, 1862-1870, 1974.

12) Rhoton A: The posterior cranial fossa. Microsurgical anatomy \& surgical approaches. Jugular foramen. Neurosurgery supplement 47:267-285, 2000.

13) Satomi J, Satoh K, Matsubara S, et al: Angiographic changes in venous drainage of cavernous sinus dural arteriovenous fistulae after palliative transarterial embolization or observational management: a proposed stage classification. Neurosurgery 56:494-502, 2005.

\section{要 旨}

JNET 5:68-73, 2011

【目的】海綿静脈洞部硬膜動静脈瘦（CS d A VF）に対する経静脈的塞栓術で, マイクロカテーテル（MC）プルア ップ法が有用だった 1 例を報告する。【症例】 76 歳, 女性. CS d A VFによる右眼症状を認めた。通常の方法では 右 CSへ到達できなかった。 ガイドワイヤー（GW）を左下錐体静脈洞（IPS）から posterior intercavernous sinus と右 IPS を介し右内頝静脈（IJV） へ誘導，右IJVの近位から誘導したグースネックスネアで捕捉した. $\mathrm{GW}$ と共にグースネックスネアと MC を右 IPSへ引き上げ, さらに右 CS 内へ誘導しコイル塞栓を施行, 症状は 消失した。【結論】 MC プルアップ法は, CS 到達困難な症例に有効な場合がある. 